American Journal of Pharmaceutical Education 2017; 81 (9) Article 6014.

\title{
RESEARCH
}

\section{Reassessment of Health-System Capacity for Experiential Education Requirements}

\author{
Matthew J. Gibson, PharmD, ${ }^{\text {a }}$ Lynette R. Bradley-Baker, PhD, ${ }^{\mathrm{b}}$ Colleen G. Bush, BS, ${ }^{\mathrm{c}}$ \\ Steven P. Nelson, $\mathrm{MS}^{\mathrm{d}}$

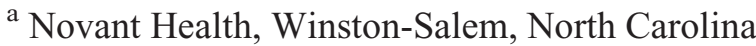 \\ ${ }^{\mathrm{b}}$ American Association of Colleges of Pharmacy, Alexandria, Virginia \\ ${ }^{\mathrm{c}}$ American Society of Health-System Pharmacists, Bethesda, Maryland \\ ${ }^{\mathrm{d}}$ Center on Pharmacy Practice Advancement, Bethesda, Maryland \\ Submitted August 17, 2016; accepted May 14, 2017; published November 2017.
}

Objective. To provide an update to the 2007 ASHP-AACP survey by examining the current capacity of hospitals/health systems' ability to conduct experiential education for doctor of pharmacy students. Methods. Pharmacists identified as pharmacy directors were sent an invitation to participate in an online survey tool. The survey tool asked IPPE- and APPE-specific questions, the nature of support provided by colleges/schools of pharmacy, the types of experiences available for students, and the factors influencing the quality, value, and challenges of experiential education.

Results. Four hundred sixty five of the 2,911 surveys sent were completed yielding a response rate of $16 \%$. Respectively, $45.1 \%$ and $28.5 \%$ of respondents believe that the capacity for APPE and IPPE will increase in the next five years. Overall, respondents believe that students receive a high-quality experiential education $(91.4 \%)$.

Conclusion. The results of this survey provide insight to the capacity, benefits and challenges of experiential education from the perspective of hospitals/health systems.

Keywords: Experiential education, APPE, IPPE

\section{INTRODUCTION}

The quality and capacity of experiential education for doctor of pharmacy students continues to be a top priority in the profession of pharmacy. The Accreditation Council for Pharmacy Education (ACPE) Standards 2007, with the institution of Introductory Pharmacy Practice Experiences (IPPEs) and other experiential education requirements, served as an impetus for a collaboration between the American Association of Colleges of Pharmacy (AACP) and the American Society of Health-System Pharmacists (ASHP) to investigate and identify the capacity for hospital/health systems' ability to serve as experiential education sites for colleges and schools of pharmacy. ${ }^{1,2}$ Results of the 2007 study suggested that hospitals/health-systems had the capacity to provide experiential education to students through 2012, as well as future capacity to provide students with IPPEs. Recognizing the need for more and updated information on the capacity for hospitals/health-systems to provide experiential

Corresponding Author: Matthew J. Gibson, 3334

Healy Drive, Winston-Salem, NC 27103. Tel: 336-718-5755. E-mail: mgibson@novanthealth.org education to students, AACP and ASHP collaborated to delve deeper into these issues.

Experiential education has had significant expansion, discoveries and actions since the implementation of Standards 2007, which mandated that experiential education constitute no less than $30 \%$ of the pharmacy education curriculum. Growth in the number of colleges and schools of pharmacy from 2007 to fall 2015 increased from 103 to 133 institutions (a 23\% increase) and enrollment has increased by $21 \%$ from 50,691 to over 63,460 students. ${ }^{3,4}$ Regional/state level consortia among pharmacy schools have increased with over 70 institutions currently participating in 11 different consortia. ${ }^{5}$ The American Journal of Pharmaceutical Education (AJPE) published a themed issue focused on scholarly work and commentary on experiential education in 2012. While the scope of the themed issue was broad, it highlighted a historical view of experiential education, as well as new views and approaches being taken by pharmacy schools to better integrate experiential education into the pharmacy curriculum. ${ }^{6}$ Additional literature surrounding IPPEs and various designs of IPPE programs also began to appear as IPPE sites now currently outnumber Advanced 


\section{American Journal of Pharmaceutical Education 2017; 81 (9) Article 6014.}

Pharmacy Practice Experience (APPE) sites twofold and the resources allocated by pharmacy schools has increased to meet the needs of experiential education. ${ }^{7}$ Experiential education teams have also grown and now consist of five or more faculty and staff led by an assistant/associate dean. ${ }^{7,8}$

Colleges and schools of pharmacy still face challenges in finding experiential education placements for their students. ${ }^{9}$ As noted by Danielson and colleagues, concerns around the capacity for hospitals/health-systems to serve as experiential education sites still exist. ${ }^{7}$ While these exact concerns were raised in the 2007 study, they did not account for changes to the experiential education curriculum with the implementation of Standards 2007. The implementation of ACPE Standards 2016 continues the requirement of utilizing hospitals/health-systems practice sites for both IPPEs and APPEs. ${ }^{10}$ Therefore, an examination of the current capacity of experiential education in hospitals/health-systems is warranted.

The purpose of this survey is to provide an update to the 2007 survey by examining the current capacity of hospitals/health systems' ability to conduct experiential education for doctor of pharmacy students. This report will not only provide information on the ability of hospitals/ health-systems to participate in and conduct IPPEs and APPEs, but will provide insight on how hospitals/healthsystems can partner with colleges and schools of pharmacy in areas pertaining to experiential education.

\section{METHODS}

An online survey was developed and distributed using Qualtrics software, version 2012 (Qualtrics Research Suite, Provo, UT) by our research team which was comprised of a clinical pharmacy manager at Novant Health, one AACP staff member, and two ASHP staff members. The survey was administered by ASHP staff to ASHP members. No IRB approval was necessary.

The 2007 survey instrument was the starting point for developing the survey so that comparisons could be made between the data collected in 2007 and 2015. The first questions on the survey were screening questions to determine which of three routes the respondents would be directed. The first route included respondents not at the study qualifying sites. A qualifying site was defined as those representing community, academic, or government hospitals, ambulatory care, VA, or long-term care sites. These respondents were directed to the end of the survey after inviting open-end text comments about experiential education. The second route included respondents at qualifying sites that did not conduct experiential education in the previous 12 months. These respondents were directed to a set of questions to determine the circumstances and barriers preventing them from conducting experiential education. The third route included respondents at qualifying sites that indicated that they did conduct experiential education in the previous 12 months. These respondents were presented with the longest question set and are the crux of the study analysis. Qualifying respondents were asked key site demographics, other background information, and questions to determine present and future projections for IPPE and APPE in the next five years.

Since additional questions related to IPPEs and APPEs were being added to the original 2007 survey, the research team examined ways to shorten and simplify an already long and complex survey. Two key approaches were taken to reduce survey length and respondent fatigue. First, sites were asked if they conducted experiential education and if so, if they conducted IPPE only, APPE only, or both IPPE and APPE. For those sites that conduct both IPPEs and APPEs, the survey tool randomly assigned them to respond to either the IPPE- or APPEspecific questions. Sites that only conducted IPPE received the IPPE-specific questions and those that only conducted APPE received only the APPE-related questions. Secondly, sites were asked to provide response categories with broad ranges (ie, 50-100) rather than requesting specific numerical information (which was the approach in 2007). Examples include questions such as the current and projected number of IPPE and APPE students and the number of full-time equivalent (FTE) pharmacists on site.

IPPE and APPE-specific questions were asked, including the factors on which expansion of involvement in experiential education would depend, the nature of support provided by colleges and schools of pharmacy, the types of experiences available for students, and the factors influencing the quality, value, and challenges of experiential education. Survey respondents were not required to answer every question.

To ensure clarity and intent of the survey questions, the revised survey instrument was pretested by conducting cognitive interviews with three pharmacists on staff at ASHP and interviews with three associate directors at The Ohio State University Wexner Medical Center. ${ }^{11,12}$ In addition, the draft survey was pilot tested by 10 pharmacy directors. The techniques for shortening and simplifying the survey were confirmed in the interviews and pilot tests and only minor changes to the wording of the questions were made based on the feedback provided.

An email was sent on June 24, 2015 to pharmacists identified in ASHP membership records as pharmacy directors and having an email address on record. The email explained the purpose of the survey, asked for participation and provided a link to access the online survey. Three 


\section{American Journal of Pharmaceutical Education 2017; 81 (9) Article 6014.}

reminder emails were sent to non-responders before the survey was closed on July 16, 2015.

Data were analyzed with IBM SPSS 21.0 (IBM Corporation, Armonk, NY). Descriptive statistics including frequency tables were used almost exclusively. Chi $\left(\chi^{2}\right)$ squared test was used to test for significance for ordinal and nominal data. The a priori level of significance was set at 0.05 .

\section{RESULTS}

Surveys were sent to 2,911 ASHP members identified as directors of pharmacy. Four hundred and sixty five surveys were completed yielding a response rate of $16 \%$. Of the 465 respondents, 382 practiced at a qualified site. Only 38 of the 382 respondents stated they did not conduct experiential education in the previous 12 months with the expectation that experiences would continue to be offered in the next year. The primary reasons sites have not partnered with a college/school of pharmacy to conduct experiential education were similar for IPPE and APPE and included never being approached by a college/school of pharmacy, limited time for pharmacy staff to serve as preceptors, and insufficient training experiences to meet objectives.

The following results reported include the responses from 344 respondents whose site conducted experiential education experiences in the previous 12 months. The demographic characteristics of sites participating in experiential education provides insight to the contributing hospitals/health-systems (Table 1). The majority of participating sites are non-profit hospitals $(62.2 \%)$, are located in urban/suburban areas (64.6\%), are part of a multihospital/health-system (67.5\%), do not have the education of health professional students in the mission of their organizations (62.6\%), and do not participate in ASHP-accredited residency training (55.4\%). There was an increase in the percentage of all respondents' participation in ASHPaccredited pharmacy residency training from $29 \%$ in the 2007 survey to $41 \%$ in the 2015 survey $\left(x^{2}=2.36, d f=1\right.$, $p=.01$ ). Of those who conducted experiential education, $44.6 \%$ conducted residency training. This provides an excellent opportunity for pharmacy residents to be involved in experiential education, which is indicated by the percentage of pharmacy residents reported to serve as preceptors in the 2015 survey (65.5\% of Postgraduate Year 1 [PGY1] residents serve as preceptors and 72.4\% of Postgraduate Year 2 [PGY2] residents serve as preceptors). In addition, 43 states were represented in the respondents.

Ninety percent of respondents conducted experiential education in the previous 12 months. Of these sites that conducted experiential education, $81.4 \%$ conducted both Introductory Pharmacy Practice Experiences (IPPEs) and Advanced Pharmacy Practice Experiences (APPEs), $7.6 \%$ conducted only IPPEs and $11.0 \%$ conducted only APPEs. In the previous 12 months, $29.3 \%$ of respondents conducted 3-5 IPPEs, 27.4\% conducted 1-2 IPPEs, 21.1\% conducted 6-10 IPPEs, 15.6\% conducted 11-25 IPPEs and $5.9 \%$ conducted over 25 IPPEs. The most common experience structure for IPPEs was daily (73.4\%), weekly (16.9\%), biweekly (6.5\%), and monthly (1.6\%). For APPEs conducted in the previous 12 months, $24.3 \%$ of respondents conducted 6-10 APPEs, $22.1 \%$ conducted 11-25 APPEs, 18.8\% conducted 3-5 APPEs, $17.8 \%$ conducted over 25 APPEs, and $16.7 \%$ conducted $1-2$ APPEs. The factors that contributed to the site's decision to conduct experiential education were similar among IPPEs and APPEs with the most frequently reported reasons indicated as giving back to the profession (82.3\% for IPPEs and $81.4 \%$ for APPEs), taking an active role in training future pharmacists $(69.4 \%$ for IPPEs and $78.6 \%$ APPEs) and engaging and challenging pharmacists to continue to develop knowledge $(50.0 \%$ for IPPEs and $62.1 \%$ APPEs).

The most common ways in which sites are supported by colleges and schools of pharmacy is based upon an affiliation agreement or contract $(60.2 \%)$, followed by continuing professional development opportunities for preceptors $(43.7 \%)$ and non-financial support (33.9\%). The total number of colleges and schools of pharmacy that the sites partnered with to provide IPPEs or APPEs was similar. Sixty-seven percent of sites partnered with 1-2 pharmacy schools for IPPEs compared to $64.3 \%$ for APPEs. Twentythree percent of sites partner with 3-4 pharmacy schools for IPPEs compared to $25.9 \%$ for APPEs. Only $7.9 \%$ and $9.8 \%$ of experiential sites partner with five or more pharmacy schools for IPPEs and APPEs respectively. The most common type of APPE conducted at experiential sites was health-system pharmacy $(79.5 \%)$, followed by general medicine $(65.8 \%)$, electives $(47.9 \%)$, ambulatory care $(34.9 \%)$, and community (19.2\%).

Many respondents believe that participation in experiential education brings value to the organization (Table 2). Stimulating staff to maintain knowledge had the highest level of agreement $(85.7 \%$ agreed or strongly agreed) among respondents followed by students being assigned to activities that are mutually beneficial to them and the organization ( $82.9 \%$ agreed or strongly agreed). Students sharing their insights and perspectives about developments in health care/pharmacy and to improve services at the sites were also highly agreeable among respondents. Less than half $(45.2 \%)$ of respondents agreed or strongly agreed that students provide additional patient care that would otherwise not be provided. 


\section{American Journal of Pharmaceutical Education 2017; 81 (9) Article 6014.}

Table 1. Characteristics of Respondents Conducting Experiential Education

\begin{tabular}{|c|c|}
\hline Characteristic & Percentage of Respondents (\%) \\
\hline \multicolumn{2}{|l|}{ Practice setting $(n=344)$} \\
\hline Academic medical center & 16.3 \\
\hline Ambulatory care & 2.3 \\
\hline Community hospital, non-profit & 62.2 \\
\hline Community hospital, for profit & 11.9 \\
\hline Government hospital & 4.1 \\
\hline Long-term care facility & 1.7 \\
\hline Veterans Affairs hospital & 1.5 \\
\hline \multicolumn{2}{|l|}{ Average daily census $(n=268)$} \\
\hline$<100$ & 31.0 \\
\hline 100-199 & 21.6 \\
\hline 200-399 & 24.3 \\
\hline$\geq 400$ & 23.1 \\
\hline \multicolumn{2}{|l|}{ Site location $(n=271)$} \\
\hline Rural & 35.4 \\
\hline Urban/suburban & 64.6 \\
\hline \multicolumn{2}{|c|}{ Education of health professional students in mission of organization $(n=340)$} \\
\hline Yes & 37.4 \\
\hline No & 62.6 \\
\hline \multicolumn{2}{|l|}{ Multi-hospital health-system $(\mathrm{n}=329)$} \\
\hline Yes & 67.5 \\
\hline No & 32.5 \\
\hline \multicolumn{2}{|c|}{ ASHP-accredited residency training $(n=271)$} \\
\hline Yes & 44.6 \\
\hline No & 55.4 \\
\hline \multicolumn{2}{|c|}{ Number of ASHP-accredited pharmacy residents PGY1 (n=123) } \\
\hline $0-1$ & 9.8 \\
\hline $2-3$ & 43.9 \\
\hline $4-5$ & 19.5 \\
\hline$>5$ & 26.8 \\
\hline \multicolumn{2}{|c|}{ Percentage of pharmacy residents that serve as preceptors } \\
\hline PGY1 $(n=119)$ & 65.5 \\
\hline PGY2 (n=58) & 72.4 \\
\hline \multicolumn{2}{|c|}{ Areas in which experiential education is offered $(n=284)$} \\
\hline Medicine & 73.2 \\
\hline Nursing & 92.3 \\
\hline Allied health & 78.5 \\
\hline Other & 8.5 \\
\hline
\end{tabular}

Overall, respondents believe that students receive a high-quality experiential education $(91.4 \%$ agreed or strongly agreed) and that pharmacists are professionally committed ( $82.0 \%$ agreed or strongly agreed). The activities that students have the opportunity to participate in are listed in Table 3. The most common activities reported include access to the electronic medical record (96.1\%), integration into team-based care $(84.5 \%)$, staff education (83.9\%), documenting clinical interventions $(82.4 \%)$, and drug information services $(81.2 \%)$. 


\section{American Journal of Pharmaceutical Education 2017; 81 (9) Article 6014.}

Table 2. Value that Experiential Education (IPPE and/or APPE) Brings to the Organization

\begin{tabular}{|c|c|c|c|c|c|}
\hline Item & $\begin{array}{c}\text { Strongly Disagree } \\
\text { n }(\%) \\
\end{array}$ & n (\%) & n (\%) & n (\%) & $\begin{array}{c}\text { Strongly Agree } \\
\text { n (\%) }\end{array}$ \\
\hline $\begin{array}{l}\text { Being placed in roles as preceptors stimulates } \\
\text { my staff to maintain their own knowledge } \\
\text { and stay up-to-date. }\end{array}$ & $3(1.0)$ & $5(1.7)$ & $34(11.5)$ & $116(39.3)$ & $137(46.4)$ \\
\hline $\begin{array}{l}\text { Students share insights and perspectives that } \\
\text { are helpful in improving services at my site. }\end{array}$ & $5(1.7)$ & $25(8.5)$ & $66(22.4)$ & $127(43.2)$ & $71(24.1)$ \\
\hline $\begin{array}{l}\text { Students share insights and perspectives about } \\
\text { general developments in health care } \\
\text { and pharmacy. }\end{array}$ & $6(2.0)$ & $27(9.2)$ & $89(30.3)$ & $117(39.8)$ & $55(18.7)$ \\
\hline $\begin{array}{l}\text { Students are assigned to activities that are } \\
\text { mutually beneficial to them and to my } \\
\text { organization (eg, assisting with literature } \\
\text { searches, medication reconciliation, service } \\
\text { improvement projects). }\end{array}$ & $1(0.3)$ & $10(3.4)$ & $39(13.3)$ & $128(43.7)$ & $115(39.2)$ \\
\hline $\begin{array}{l}\text { Students provide additional patient care that } \\
\text { would otherwise not be provided (ie, } \\
\text { medication reconciliation, patient counseling). }\end{array}$ & $30(10.2)$ & $52(17.7)$ & $79(26.9)$ & $77(26.2)$ & $56(19.0)$ \\
\hline Students add value to my organization. & $1(0.3)$ & $8(2.8)$ & $50(17.4)$ & $131(45.5)$ & $98(34.0)$ \\
\hline
\end{tabular}

Abbreviations: APPE $=$ Advanced Pharmacy Practice Experiences. IPPE $=$ Introductory Pharmacy Practice Experiences

Table 4 displays the projected capacity (students per year) for both IPPEs and APPEs in the next five years. Forty-five percent of respondents believe that the capacity for APPEs will increase compared to $28.5 \%$ of respondents who believe the capacity for IPPEs will increase. Only $7.7 \%$ and $6.3 \%$ of respondents believe that their capacity for IPPEs and APPEs will decrease over the next five years, respectively. The factors that most heavily influence the practice site's capacity to participate in experiential education are the ability for the practice model to accommodate students (22.4\%), willingness of preceptors to take on students $(18.2 \%)$ and the number of clinical pharmacists (10.6\%). Twenty-nine percent of sites had 1-2 or 3-5 preceptors who participate in experiential education (IPPE and/or APPE). Nineteen percent had 6-10 preceptors and $23.4 \%$ reported having more than 10 preceptors at their site.

Inferential statistical tests were performed to determine any statistically significant differences in respondent characteristics and the number of IPPE and APPE rotations. There was a statistically significant difference between the number of IPPEs $\left(\mathrm{x}^{2}=76.90, \mathrm{df}=12, p=.00\right)$ and APPEs $\left(\mathrm{x}^{2}=91.31, \mathrm{df}=12, p=.00\right)$ and the average daily census. The sites that had a larger average daily census provided more IPPEs and APPEs. In addition, the sites that had more pharmacist full-time equivalents
(FTE) offered more IPPE $\left(\mathrm{x}^{2}=111.14, \mathrm{df}=16, p=.00\right)$ and APPE $\left(\mathrm{x}^{2}=91.18, \mathrm{df}=16, p=.00\right)$ student rotations. The top potential solutions (Table 5) chosen by the respondents to address the increase in demand for experiential education include securing placement of faculty at sites funded or co-funded by colleges/schools (60.8\%), initiating experiences in hospitals/health-systems where they are not currently conducted (55.7\%) and training more existing hospital/health-system pharmacists to be preceptors $(55.7 \%)$.

There was some variation in the primary challenges to increasing the quality or quantity for IPPEs compared to APPEs (Tables 6 and 7, respectively). Time for pharmacy staff to serve as preceptors was the response that had the highest percentage of respondents for both IPPEs (35.0\%) and APPEs (41.8\%). Thirteen percent (second highest percentage) of respondents believe that the burden to conduct orientation was the primary challenge to increasing the quantity or quality of IPPEs. The second most chosen response for APPEs was insufficient standardization among colleges/schools of pharmacy. The site not being geographically close (as interpreted by the respondents) to a college/school of pharmacy was the third most reported challenge among respondents for both IPPEs (10.3\%) and APPEs (11.3\%). The factors reported that most heavily influence the quality of experiential 


\section{American Journal of Pharmaceutical Education 2017; 81 (9) Article 6014.}

Table 3. Activities that IPPE and/or APPE Students Have the Opportunity to Participate in During Experiential Education

\begin{tabular}{lc}
\hline Activities (N=330) & Percentage of Respondents (\%) \\
\hline Access to the electronic medical record (EMR) & 96.1 \\
Integration into team-based care (rounding with patient care team) & 84.5 \\
Staff education (ie, presentations for staff) & 83.9 \\
Documenting clinical interventions that are shared with pharmacists and other & 82.4 \\
$\quad$ health care providers & 81.2 \\
Drug information services & 79.4 \\
Detection and handling of adverse drug reactions & 75.2 \\
Medication use evaluation & 74.5 \\
Interdisciplinary committee meetings to establish medication-use protocols or & 74.5 \\
$\quad$ other medication-use policies and procedures & 73.3 \\
Patient teaching/education & 70.3 \\
Administration activities & 69.4 \\
Medication error prevention and detection & 68.5 \\
Collaborative drug therapy management & 65.2 \\
Preparation of sterile products & 60.6 \\
Obtain medication history & 60.0 \\
Medication discharge counseling & 46.7 \\
Therapeutic decision-making on behalf of specific patients & \\
Medication therapy management services & \\
\hline
\end{tabular}

Abbreviations: APPE $=$ Advanced Pharmacy Practice Experiences. IPPE = Introductory Pharmacy Practice Experiences

education include availability of staff to serve as preceptors $(65.9 \%)$, the desire/commitment of pharmacy staff to serve as preceptors $(62.3 \%)$, and experience and competence of preceptors as practitioners and educators $(49.4 \%)$.

\section{DISCUSSION}

Experiential education is a very important and predominant component in the training of doctor of pharmacy students. This survey, which is a follow-up to a 2007 experiential capacity survey of U.S. pharmacy directors, provides updated insight as to the capacity, benefits and challenges of experiential education in hospitals/healthsystems.

This investigation provides information from ASHP members (directors of pharmacy) on the hospital/healthsystem sites participating in experiential education. This information includes demographic characteristics as well as the respondents' perceptions pertaining to the benefits and challenges of experiential education. It is important that colleges/schools of pharmacy continue to collaborate with existing participants to expand the IPPE and APPE opportunities while also reaching out to the hospitals/health-systems that are not participating in experiential education to establish opportunities.

This survey provides information on IPPEs which was not available in the 2007 survey. Eighty-nine percent of the respondents participated in IPPEs, either solely or concurrently with APPEs. Definitive responses regarding the factors that contribute to a site's decision to conduct IPPEs, projected capacity (students per year) for IPPEs, challenges to increasing the quality or quantity of IPPEs, and current IPPE structure (for those respondents assigned this block of questions via the randomization scheme described earlier) were collected. Interestingly, the ranking of the factors that contribute to a site's decision to conduct IPPEs or APPEs were the same, which suggests that hospitals/health-systems are committed to serving as experiential sites for future pharmacist practitioners. Experiential education departments have the opportunity to impact the two most cited challenges to increasing the quality and quantity of IPPEs (Table 6) by providing preceptor training and continuing educational development as well as working directly with hospitals/ health-systems to develop more efficient methods for student pharmacist orientation to hospitals/health-systems.

Table 4. Projected Capacity (Students Per Year) for Experiential Education Five Years From Now

\begin{tabular}{lccc}
\hline & Capacity will Decrease (\%) & Capacity will Stay the Same (\%) & Capacity will Increase (\%) \\
\hline IPPE $(n=298)$ & 7.7 & 63.8 & 28.5 \\
APPE $(n=284)$ & 6.3 & 48.6 & 45.1 \\
\hline
\end{tabular}




\section{American Journal of Pharmaceutical Education 2017; 81 (9) Article 6014.}

Table 5. Potential Solutions to Address Increase in Demand for Experiential Education (IPPE and/or APPE)

Solutions $(\mathbf{N}=\mathbf{2 9 6})$

Percentage of Respondents (\%)

Secure placement of faculty at your site funded or co-funded by colleges/schools.

60.8

Initiate Experiences in hospitals and health-systems where they are not now conducted. 55.7

Train more existing hospital and health-system pharmacists to be preceptors.

55.7

Schedule Experiences in evenings and weekends.

35.1

Assign multiple students to preceptors at the same time.

32.1

Allow more non-pharmacists to serve as preceptors of record.

10.1

Abbreviations: APPE $=$ Advanced Pharmacy Practice Experiences. IPPE = Introductory Pharmacy Practice Experiences

This survey provides some of the first documented data on the structure of IPPEs in hospitals/health-systems from the experiential site's perspective. Daily student IPPE experiences $(73.4 \%)$ were overwhelmingly the most predominant structure reported. Additional insight as to student pharmacist activities during IPPEs as well as health-systems' preferences for the structure of IPPEs is warranted.

Projected capacity for experiential education appears to be promising. The majority of respondents projected capacity for experiential education to either stay the same or increase (Table 4). These estimates, coupled with the value that experiential education brings (Table 2 ), provide the profession with viable information to continue to enhance and extend the experiential education opportunities in hospitals/health-systems.

The three most influential factors that contributed to a site's decision to conduct both IPPEs and APPEs were giving back to the profession, taking an active role in training future pharmacists, and engaging and challenging pharmacists to continue to develop knowledge. The 2007 survey has the same top two factors with the third factor being the ability to recruit residents or future employees. The ability to recruit residents or future employees is the current survey's fourth rated factor contributing to a site's decision to conduct both IPPEs (41.1\%) and APPEs (51.7\%). While recruitment of future employees is important and still relevant to experiential education, a sign that experiential education is continuing to evolve to benefit pharmacists is indicated as it provides a mechanism to engage and challenge practitioners to continue their professional development. The influence of the ASHP Practice Advancement Initiative $(\mathrm{PAI})^{13}$ which evolved from the Pharmacy Practice Model Initiative (PPMI) is apparent in the primary experiential education participation factor cited by respondents.

Table 6. Primary Challenge to Increasing Quality or Quantity of IPPE

Challenge ( $n=117$, top 6 of 15 responses displayed)

Time for pharmacy staff to serve as preceptors is limited.

Burden to conduct orientation (eg, orientation to computer systems, layout of site, patient privacy policies, dress codes, site security/access, parking) for students participating in IPPEs at my site.
My site is not geographically close to a college/school of pharmacy.

10.3

Academic schedules for IPPEs are incompatible with assigning students to activities that are mutually beneficial to them and to my organization (eg, assisting with medication reconciliation, service improvement projects).

Insufficient standardization and coordination of IPPEs among colleges/schools

(eg, different start and end dates, objectives, evaluation tools, etc.).

Lack of availability or affordability of housing for students in close proximity to my site.

${ }^{a}$ Includes nine other response categories; each received less than five responses 


\section{American Journal of Pharmaceutical Education 2017; 81 (9) Article 6014.}

Table 7. Primary Challenge to Increasing Quality or Quantity of APPE

\begin{tabular}{lc}
\hline Challenge (n=141, top 9 of $\mathbf{1 5}$ responses displayed) & Percentage of Respondents (\%) \\
\hline Time for pharmacy staff to serve as preceptors is limited. & 41.8 \\
& \\
Insufficient standardization and coordination of Advanced Experiences (APPEs) & 11.3 \\
among colleges/schools (eg, different start and end dates, objectives, \\
evaluation tools, etc.).
\end{tabular}

My site is not geographically close to a college/school of pharmacy.

Academic schedules for Advanced Experiences are incompatible with 4.3 assigning students to activities that are mutually beneficial to them and to my organization (eg, assisting with medication reconciliation, service improvement projects).

Burden to process student prerequisites (ie, criminal background checks, immunization records, drug screens, etc.) required by my site for students participating in Advanced Experiences.

I would rather allocate my staff time to precepting residents than students.

Insufficient support at the administrative level (above pharmacy director).

Lack of a standardized needs assessment tool (across colleges/schools) to evaluate students' previous experience and knowledge about hospitals and health-systems prior to entering Advanced Experiences (APPEs).

Burden to conduct orientation (eg, orientation to computer systems, layout of site, patient privacy policies, dress codes, site security/ access, parking) for students participating in Advanced Experiences at my site.

All other response categories. ${ }^{\mathrm{a}}$

${ }^{a}$ Includes six other response categories; each received less than four responses

The PAI aspires to transform how pharmacists care for patients by empowering the pharmacy team to take responsibility for medication-use outcomes. During experiential education, student pharmacists can become part of the pharmacy team and can contribute to the PAI.

The survey provides some valuable information regarding the benefit and value of experiential education to hospitals/health-systems. Overall respondents agreed that student pharmacists' participation in experiential education provides benefits to both the student and health-systems. The most common activities identified that students have the opportunity to participate in were access to the electronic medical record (EMR) (96.1\%), integration into team-based care (rounding with patient care team) $(84.5 \%)$, staff education $(83.9 \%)$, documenting clinical interventions that are shared with pharmacists and other health care providers (82.4\%), and drug information services $(81.2 \%)$. These and the other reported student pharmacist activities in hospitals/health-systems during IPPEs and APPEs allow them to contribute to the roles and responsibilities of health-system pharmacists as well as influence patient care. These activities also allow for an extension of the hospital/health-system pharmacist and pharmacy roles in the institution, which can lead to an increase in patient care services and potentially improve patient care outcomes.

The results from the 2015 survey are very similar to those of the 2007 survey with regards to experiential education challenges. Time for pharmacy staff to serve as preceptors being limited was cited as the primary challenge to increasing the quality or quantity of both IPPEs (35.0\%) and APPEs (41.8\%) in the current survey and was the primary challenge cited for experiential education in the 2007 survey. The lack of time to serve as a preceptor can be attributed to several areas, including lack of qualified preceptors due to the absence of appropriate preceptor training, the lack of exploration on how student pharmacists in experiential education can influence or 


\section{American Journal of Pharmaceutical Education 2017; 81 (9) Article 6014.}

enhance the workload and services of the health-system, and the workload of pharmacy staff during a time in health care that demands efficient use of resources. Preparation of preceptors is a priority for experiential education departments at colleges and schools of pharmacy and there are a variety of mechanisms (ie, ASHP's annual pharmacy preceptor conference, ASHP preceptor skills resource center, colleges and schools of pharmacy preceptor development program[s]) that can be utilized for training and preparation. The utilization of student pharmacists on IPPEs and APPEs to participate and contribute to the needs of the site would not only add to the student pharmacist training, but may also provide a more efficient use of the preceptor's time at the site.

The other top challenges to increasing IPPEs included the burden to conduct student orientation (12.8\%), sites not being geographically close to a pharmacy school $(10.3 \%)$, and academic scheduling for IPPEs not being compatible for the activities that would be beneficial for both student pharmacists and the site (6.8\%). Challenges to increasing APPEs included insufficient standardization and coordination of APPEs among colleges/schools of pharmacy $(11.3 \%)$ and the site not being geographically close to a college/school of pharmacy (11.3\%). Standardization of experiential education elements such as scheduling, orientation, and evaluations among colleges/schools of pharmacy on a local, regional and national level would assist sites by reducing some of the current inconsistencies, especially among those sites that take student pharmacists from more than one institution. Collaborative relationships between pharmacy schools and hospitals/health-systems could provide multiple solutions to assist with these consistency elements.

The potential solutions (Table 5) to address the increase in demand for experiential education provides valuable information for sites to provide experiential education and for colleges and schools of pharmacy to expand the network of experiential education. Examples cited include secure placement of pharmacy faculty at sites that are funded or co-funded by colleges and schools of pharmacy, initiation of experiential education in hospitals/ health-systems where they are not currently conducted, train more hospital/health-system pharmacists to be preceptors, schedule experiences in evenings and on weekends, and assign multiple students to preceptors at the same time.

The 2007 experiential education capacity survey provided several action priorities for AACP, ASHP, and other stakeholders to provide guidance to enhancing the capacity, quality, efficiency, and success of partnerships for experiential education. While some progress has been made with the action priorities, there are areas that need continued focus. The findings from this survey suggest three major strategic recommendations that colleges and schools of pharmacy and hospital/health-system practice organizations should continue to expand on in the future. First, academic pharmacy and hospitals/health-systems should collaborate to ensure the availability and standardization of the educational preparation and continuing professional development of preceptors. Second, academic pharmacy and hospitals/health-systems should work in partnership at the national, regional and local levels on developing and expanding the use of innovative approaches to providing experiential education which maximizes the benefit for all stakeholders. Third, AACP and ASHP should collaborate to document and communicate the value of experiential education partnerships between academic pharmacy and hospitals/health-systems to stimulate, sustain and encourage participation in experiential education.

Standardization in the preparation of preceptors and their continued professional development of preceptor skills would be beneficial for all experiential education stakeholders. Academic pharmacy should support or provide educational programs to facilitate the initial and continued development of pharmacy preceptors. This is mandated by the ACPE accreditation standards and preceptors are now the focus of a single standard (standard 20). ${ }^{14}$ The continuing professional development needs of preceptors continue to evolve and several programs developed by colleges and schools of pharmacy have been described in the literature. ${ }^{15,16}$

ASHP can also have a role in contributing to the availability and standardization of the educational preparation and continuing professional development of preceptors. With the increase in residency training occurring at hospitals/health-systems from the 2007 survey (29\%) to the current survey (41\%), pharmacy residents are potential avenues to assist with the experiential education training of student pharmacists. Incorporating preceptor education/training into pharmacy residency programs will not only assist in the professional development of the resident, but will also extend the experiential education capacity of hospitals/health-systems.

Experiential education models that provide mutually beneficial outcomes for the student pharmacist, pharmacy school, and hospital/health-system have developed since the 2007 experiential education capacity survey. Blockscheduling is an experiential education model where student pharmacists can complete most if not all required and elective APPEs at one practice site, including an affiliated academic medical center. The advantages of block scheduling include the more efficient use of teaching resources, 


\section{American Journal of Pharmaceutical Education 2017; 81 (9) Article 6014.}

increased collaboration among preceptors, greater continuity and standardization of educational experiences, and enhanced opportunities for students to engage in longer and more complex research projects. ${ }^{17,18}$ Newer models such as block scheduling may have disadvantages and may not be appropriate for all sites. The use of layered learner models of education with clinical pharmacists, residents, IPPE students, and APPE students working on teams to provide patient care have become part of some experiential education sites. ${ }^{19}$

As pharmacy and health care continue to evolve, documentation as to the services and benefits generated from practitioners, students and systems need to be available. There are some examples of assessing the value of student pharmacists in experiential education. In a review of studies examining the value of the student pharmacist to experiential practice sites, student pharmacists were found to confer economic and clinical benefits that may exceed the costs associated with their supervision and training. ${ }^{20}$ There are several investigations involving the value generated from APPE students including an evaluation of 312 interventions in a psychiatric hospital that provided a cost avoidance of approximately $\$ 23,000,{ }^{21}$ a study that concluded that one year of APPE student pharmacists produced an estimated cost avoidance of $\$ 908,800$ during the required APPEs, ${ }^{22}$ and an assessment of all the interventions made by APPE students over the course of one academic year at one pharmacy school that provided a cost-savings of over $\$ 8$ million with 59,613 recommendations. ${ }^{23}$

Student pharmacists contribute to expanding patient care services and improving quality. Publicizing examples of student pharmacists improving metrics, such as access to and quality of patient care, will assist in developing a consensus on such metrics and expand the use of such approaches. These examples may also lead to changes in pharmacy practice legislation or pharmacy practice acts that allow for the enhanced utilization of student pharmacists in pharmacy practice sites, including health-systems.

The strengths of this survey are that it is national in scope, including respondents from hospitals in 43 states. About three-quarters of respondents worked in community hospitals which closely reflects the national percentage. The survey was designed so that it could be compared to the 2007 Capacity Survey in order to identify any significant changes and factors in pharmacy experiential education. Limitations of the survey that may be a source of bias are that it was only sent to pharmacy directors who are ASHP members, the percentage of sites that had a larger bed size was greater than the national average (more similar to ASHP membership), and the response rate was only $16 \%$. However, since the 2007 survey was also sent only to pharmacy directors belonging to ASHP, comparisons between the survey findings are reliable. To provide insight into the possibility of non-response bias, a comparison was made between early and late responders (those who responded before any reminders were sent and those who responded after reminders). When responses to key questions were compared, there were no significant differences found between the early and late responders. $^{24,25}$

\section{CONCLUSION}

The results of this survey provide insight to the capacity, benefits and challenges of experiential education from the perspective of hospitals/health systems. Further research from the perspective of the student pharmacists and/or schools and colleges of pharmacy would be beneficial. Hospitals/health systems and academia must continue to collaborate to address the challenges within experiential education and to maximize the benefits to the students, colleges, and experiential sites.

\section{REFERENCES}

1. Accreditation Council for Pharmacy Education. Accreditation standards and guidelines for the professional program in pharmacy leading to the doctor of pharmacy degree: appendix C. https://www. acpe-accredit.org/pdf/Standards2016FINAL.pdf. Accessed

November 20, 2017.

2. Scheckelhoff DJ, Bush CG, Flynn AA, et al. Capacity of hospitals to partner with academia to meet experiential education requirements for pharmacy students. Am J Health Syst Pharm. 2008;65(21):e53-e 71.

3. American Association of Colleges of Pharmacy. Profile of Pharmacy Students Fall 2007. Fall 2007 Enrollments (Professional degrees). http://www.aacp.org/resources/research/

institutionalresearch/Documents/Introduction.pdf. Accessed November 20, 2017.

4. American Association of Colleges of Pharmacy. Profile of Pharmacy Students Fall 2015: Fall 2015 Enrollments (Professional degrees). Accessed November 20, 2017.

5. American Association of Colleges of Pharmacy. AACP consortia list. http://www.aacp.org/governance/SECTIONS/

experientialeducation/Experiential\%20Education\%20Documents/ AACP\%20Consortia\%20List\%202015.xlsx. Accessed November 20, 2017.

6. American Journal of Pharmaceutical Education. Theme issue: experiential education. Am J Pharm Educ. 2012:76(3). http://www. ajpe.org/page/experiential_education. Accessed December 6, 2016. 7. Danielson J, Eccles D, Kwasnik A, Craddick K, Heinz AK, Harralson AF. Status of pharmacy practice experience education programs. Am J Pharm Educ. 2014;78(4):Article 72.

8. Devine PS, Darbishire PL. National trends in IPPE programs at US schools of pharmacy from 2008-2013. Am J Pharm Educ. 2015;79(3): Article 39.

9. Danielson J, Craddick K, Eccles D, Kwasnik A, O’Sullivan TA. A qualitative analysis of common concerns about challenges facing 


\section{American Journal of Pharmaceutical Education 2017; 81 (9) Article 6014.}

pharmacy experiential education programs. Am J Pharm Educ. 2015;79(1):Article 6.

10. Accreditation Council for Pharmacy Education. Accreditation standards and guidelines for the professional program in pharmacy leading to the doctor of pharmacy degree. Standards 2016: appendix 2. https://www.acpe-accredit.org/pdf/Standards2016FINAL.pdf. Accessed December 6, 2016.

11. Willies GB, Royston P, Bercini D. The use of verbal report methods in the development and testing of survey questionnaires. Appl Cogn Psychol. 1991;5(3):251-267.

12. Willis GV. Cognitive interviewing and questionnaire design: a training manual. Bethesda, MD: National Center for Health Statistics, 1994; US Department of Health and Human Services working paper series no. 7.

13. ASHP Practice Advancement Initiative. http://www.ashpmedia. org/pai/overview.html. Accessed December 6, 2016.

14. Accreditation Council for Pharmacy Education. Accreditation standards and key elements for the professional program in pharmacy leading to the doctor of pharmacy degree. Standards 2016. https:// www.acpe-accredit.org/pdf/Standards2016FINAL.pdf. Accessed December 6, 2016.

15. Boyle CJ, Morgan JA, Layson-Wolf, Bittner MRD. Developing and implementing an academy of preceptors. Am J Pharm Educ. 2009;73(2):Article 34.

16. Vos SS, Trewet CB. A comprehensive approach to preceptor development. Am J Pharm Educ. 2012;76(3):Article 47.
17. Hatton RC, Weitzel KW. Complete-block scheduling for advanced pharmacy practice experiences. Am J Health Syst Pharm. 2013;70(23):2144-2151.

18. Taylor RA, Wisneski SS, Kaun MA, Parteleno P, Williams J, Goldman MP. Sequential advanced pharmacy practice experiences at one institution for students from three pharmacy schools. Am J Health Syst Pharm. 2014;71(2):140-144.

19. Delgado O, Kernan WP, Knoer SJ. Advancing the pharmacy practice model in a community teaching hospital by expanding student rotations. Am J Health Syst Pharm. 2014;71(21):1871-1876. 20. Mersfelder TL, Bouthiller MJ. Value of the student pharmacist to experiential practice sites: a review of the literature. Ann Pharmacother. 2012; 46(4):541-548.

21. Campbell AR, Nelson LA, Elliott E, Hieber R, Sommi RW. Analysis of cost avoidance from pharmacy students' clinical interventions at a psychiatric hospital. Am J Pharm Educ. 2011;75(1):Article 8. 22. Woolley AB, Berds IV CA, Edwards RA, Copeland D, DiVall MV. Potential cost avoidance of pharmacy students' patient care activities during advance pharmacy practice experiences. $\mathrm{Am} \mathrm{J}$ Pharm Educ. 2013;77(8):Article 164.

23. Shepler BM. Cost savings associated with pharmacy student interventions during APPEs. Am J Pharm Educ. 2014;78(4):Article 71. 24. Johnson TP, Wislar JS. Response rates and nonresponse errors in surveys. JAMA. 2012;307(17):1805-1806.

25. Miller LE, Smith KL. Handling nonresponse issues. $J$ Ext. 1983;21:45-50. 